coherent philosophy with which to conceptualise illness and the treatment of ill people.

JAMES MATHERS

\section{Quest for Excellence in Medical Education}

Sir George Pickering, published for Nuffield Provincial Hospital Trust by Oxford University Press, I978. I02pp, £4.50.

Medical Education and Medical
Care, a Scottish - American Sym-
posium, Gordon McLachlan
(Editor), published for Nuffield
Provincial Hospital Trust by Oxford
University Press, I977, 2 I $5 \mathrm{pp}, £ 6.00$.

Sir George's recent death deprived us of one of the major figures in post-war British medicine. One of his outstanding qualities was the balance of his interest and skill in the three separate areas of clinical medicine, research and education. $\mathrm{He}$ combined these interests to an amazing and some would say unique degree, and it is this which makes the prospect of his book fascinating. There have been a large number of pressures on medical education in the last decade. Graduate output has increased. The scientific knowledge required as a background to practice has widened. New schools with new ideas have been formed, and the demands and standards of postgraduate practice have altered. There have been other challenges to expansion, however, most recently the stark economic reality of the enormous expense of medical education compared with other university courses. Medical unemployment could be a reality within a few years. Specialist and high technology medicine has been challenged at all levels, certainly by the renewed interest amongst medical students in general practice. All this should mean that medical educators are thinking hard about their task, and should be questioning the assumptions of their predecessors. Sometimes this seems to be the case, but more often the debate is confined to parochial issues, power struggles, and the defence of the status quo, ancient or modern. Sir George, asked by the Nuffield Provincial Hospital's Trust after the I 973 Pembroke Conference to survey medical education in general has avoided all the temptations of narrow thinking and has provided something that was desperately needed, a short and well written piece which asks sharp and perceptive questions, and comes up with concise but deep and well-reasoned answers. Unlike the representatives of more recent reports on medical education, he visited the institutions he concentrates on and saw what they were actually doing, not what they said they were doing. As a piece of work it seems a model of its kind.

What he found is more alarming. Medical students are brighter and keener than ever before, and yet within the schools he often found them bored, felling they were 'data banks' and asked to cram current dogma rather than develop their own minds by using their observations and learning to achieve a synthesis of their own. This runs counter to the clear need of the undergraduate to learn how to learn in order to face a professional life full of changes in emphasis and practice. The idea that a graduating doctor should be immediately able to practise in any field, although implied in the Medical Acts, Sir George exposes for the nonsense it is; but he shows that this still has not led teachers or examiners to respond suitably. Now that postgraduate education is a reality for all branches of medicine, specialist teaching should be given at this point, and yet again he points out how examinations geared to reduce the chance of a badly trained doctor slipping through, and thus keeping up standards in general, are equally discouraging to original thought, literacy and scholarship and provided dogma not education as their pabulum. These and other ideas form challenging reading which should be required for anyone who teaches in medicine at any level.

The stimulation of Sir George's short piece (and why was it not in paperback?) contrasts with the broad and leisurely symposium on the contributions which Scotland and the USA have made to medical education and care, and the problems that these two countries face in common or in contrast. For anyone interested in history this is pleasant and useful reading, but it failed, as perhaps so many symposia fail, to have a cutting edge which helps us to shape the future. Several of the contributors were first rate, but what they had to say seemed to me curiously blunted. I am sure great benefits were derived by those who attended, but I feel the Trust spends its money better for the reader when asking an individual to come up with a definitive statement, based An observation, like Sir George's, ratier than a wide series of the type survey that we find in this symposium. Which having been said, should pay tribute to the work that the Trust has done in so maxiny unusual but important and influ tial areas of medical education. May its foresight and generosity contingle to enlighten us!

ROGER HIGGS

The End of an Age of OptimismMedical Science in Retrospet and Prospect

Colin Dollery

Rock Carling Monograph, Iक्ठ Nuffield Provincial Hospitals Trust, I978, 95 pp, £3.75.

The last decade has witnessed wave of criticism of west medicine and its relationship with science. Two of the most imaginat 60 and radical attacks have come frem previous Rock Carling Fellow, Cochrane in 1972 and McKeown I976. Their monographs have been much debated and have rapiøly become medical classics. Dolle्py has therefore a difficult tradition to follow in reviewing the role $\overrightarrow{\text { Jf }}$ science in medicine, in part as $\mathbf{z} n$ answer to the critics.

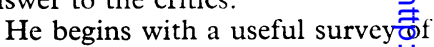
the main criticisms which he draws up in the form of a list of charges against medical science. Apart from medical conspiracy, he finds that they each have some substance, bit have been greatly exaggerated. From this he concludes that taken overat, science has served medicine woll and the acknowledged deficiencios, though not unimportant, are pepheral. It is significant that the on charge judged unequivocally @S guilty is medical 'gullibility' nir accepting new procedures and drußs, which implies the need for an even greater application of traditionl scientific method. The types of problem facing medicine are seen basically unchanged and will be best remedied by more of the sance approach, with some additions apd modifications to allow for altered circumstances. The remaining cha ters are mainly concerned with $\hat{a}_{a}$ more detailed justification and wor ing through of this theme, especialby concerning the organisatioral arrangements for research. 